\title{
Assessing outcomes after fast track surgical management of corpus cancer
}

\author{
Jonathan Carter $^{1,2^{*}}$, Shannon Philp ${ }^{1,2}$ \\ ${ }^{1}$ Sydney Gynaecological Oncology Group, Sydney Cancer Centre, Royal Prince Alfred Hospital, Sydney, Australia; \\ ${ }^{2}$ The University of Sydney, Sydney, Australia. \\ E-mail: ${ }^{*}$ jocarter@mail.usyd.edu.au
}

Received 12 June 2011; revised 15 July 2011; accepted 22 July 2011.

\begin{abstract}
Objective: The aim of the study was to audit the outcomes of patients with corpus cancer managed with a fast track surgery (FTS) program. Design: Clinical audit of outcomes after laparotomy for corpus cancer and managed by FTS principles. Setting: Tertiary hospital, University based subspecialty gynaecological oncology practice. Population or Sample: Consecutive patients with uterine corpus cancer. There were no exclusions. Methods: Three year audit of FTS Database. Main Outcome Measures: Ability to tolerate early oral feeding (EOF), length of stay (LOS), perioperative complication rate and readmission rate. Results: Sixy six patients were operated upon whose median age was 59.5 years. Forty six $(\mathbf{7 0} \%)$ had stage I disease, 7 (11\%) stage II, 9 (14\%) stage III and 4 (6\%) had stage IV disease. Twenty seven (41\%) had lymph node sampling performed. Median operating time was 2.5 hours. Mean BMI was $30 \mathrm{~kg} / \mathrm{m}^{2}$ (Range: 18 - 47). Fifty patients ( $76 \%$ ) were classified as overweight or obese. Twenty four patients (36\%) had a “non-zero" performance status. Mean intraoperative EBL was $227 \mathrm{ml}$. Median LOS was 3.0 days. There were $3(5 \%)$ intraoperative complications. There were no intraoperative ureteric, bowel or vascular injuries. Postoperatively, 13 (20\%) patients experienced a total of 24 adverse events. Only 2 (3\%) patients experienced complications greater than grade 2 . Conclusion: This audit shows that in an unselected group of patients undergoing laparotomy as management for their uterine malignancy and managed by a FTS protocol, overall excellent results can be achieved.
\end{abstract}

Keywords: Fast Track Surgery; Clinical Audit; Corpus Cancer

\section{INTRODUCTION}

Endometrial cancer is the most common gynaecological cancer affecting women, and with an increasing incidence, a safe, cost effective and tolerated management is important [1]. Treatment remains removal of the uterus and adnexa, and this can be accomplished via laparotomy, vaginally, totally laparoscopic, laparoscopically assisted or robotically. Surgical staging to define the extent of disease may be added to hysterectomy, however the rationale for this and data on survival impact is often debated [2].

Fast track surgery programs are not new, nor are they complicated. They were first described by Kehlet in Denmark in 2002 and the principles have been adopted by most surgical specialities worldwide $[3,4]$. FTS programs incorporate a number of elements and are not just clinical pathways. Many of these elements are already practiced by surgeons, but few embrace the entirety to gain the maximum benefits for their patients. By minimising stress and maintaining normal physiology as much as possible, the catabolic stresses of surgery and anaesthesia can be minimised, optimising patient outcomes and as a consequence reducing length of stay (LOS).

Clinical audit is one of the fundamental principles of clinical governance, the process by which clinicians improve the quality of the care they provide. It provides powerful information to the consumer (patient) and health care provider (Hospital, Government) as to the outcomes really achieved in a real life scenario.

A clinical audit was undertaken of all patients referred to a single gynaecological oncologist with a diagnosis of uterine corpus malignancy and who subsequently underwent surgical management via laparotomy and managed with a FTS program. The aim of the audit was to document outcomes of patients managed with FTS and laparotomy and to provide a reference for subsequent clinical audits.

\section{METHODS}

This audit reports the experience of 3 full years of pa- 
tients referred to a single gynaecological oncologist, for the surgical management of cancer of the uterine corpus managed by a FTS program. The audit includes all patients taken to the operating room for the calendar years 2008, 2009 and 2010 who underwent a laparotomy. There were no exclusions and no exceptions. Data was collected in a real time fashion on the author's personal database and analysis undertaken in a retrospective fashion.

Our FTS program has been previously described, and involves preoperative patient counselling regarding the program by both surgeon and nurse, informing the patient of their anticipated LOS and the criteria for discharge. Patients are advised that once these criteria are met, discharge would occur. Narcotic analgesia is limited and adequate analgesia provided by a combination of intraoperative paracoxib and transverse abdominis plane (TAP) block [5,6]. Mechanical bowel preparations are not routine, fluid balance optimised to retain as close to normal intravascular volume and unnecessary tissue trauma is avoided by good surgical technique. Strict attention to haemostasis is important and drains are avoided. Postoperatively meloxicam is prescribed for 3 days with regular paracetamol. Oral liquids are allowed on the night of surgery and light diet on post op day 1 with rapid progression thereafter. Movicol or Coloxyl with Senna is commenced routinely on post op day 1 and continued post discharge. All patients receive perioperative Clexane which is continued until discharge. Selected high risk patients are offered extended Clexane prophylaxis. Intraoperatively mechanical sequential compression devices are employed and all patients have knee high TED stockings fitted and worn postoperatively for at least 1 month. Patients are mobilised day 1 post surgery and catheters and IV fluids are also removed on day 1 whenever possible. Patients are given an incentive spirometer or "Triflow" and encouraged to use the device 6 times per hour. Criteria for discharge include the patient adequately mobilising without assistance, tolerating early oral feeding, managing their pain and discomfort with oral analgesia and having adequate home supervision. Post discharge patients receive a follow up phone call from our Clinical Nurse Consultant (CNC) within 3 days of discharge.

Data collected relate to patient characteristics, hospitalisation and post-hospitalisation. The following patient characteristics were collected: age, weight, height, body mass index (BMI), medical insurance status, and performance status. Hospitalisation details included the procedure performed, type of incision (transverse or midline), operating time, complexity of surgery (simple vs. complex), intraoperative estimated blood loss (EBL), whether a transfusion was required, the preoperative $\mathrm{Hb}$, post operative $\mathrm{Hb}$ and the $\mathrm{Hb}$ change, whether the patient tolerated early oral feeding (EOF) and if the patient received COX Inhibitors. All inpatient complications were collected, including modified Royal Australian and New Zealand College of Obstetricians and Gynaecologists (RANZCOG) Quality Indicators (Table 1). Date of admission and date of discharge were used to calculate length of stay (LOS). Post hospitalisation admissions and complications were also recorded. All patients were reviewed 2 - 4 weeks post discharge.

Ethics approval was granted to allow review and presentation of the data as a clinical audit. Statistical analysis included descriptive statistics, t-test and ANOVA for nominal variables and chi-squared test for categorical data.

\section{RESULTS}

Over the 3 year audit period, 66 patients were operated upon whose median age was 59.5 years (Range: 35.1 86 years). Forty six (70\%) had stage I disease, 7 (11\%) stage II, 9 (14\%) stage III and 4 (6\%) had stage IV disease. Twenty seven (41\%) had lymph node sampling

Table 1. Quality indicators collected by the Sydney gynaecological oncology group

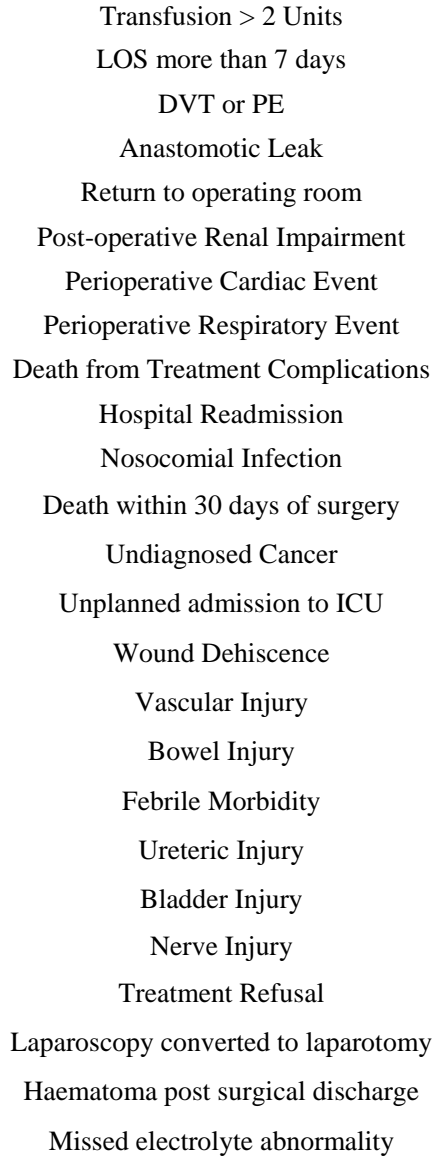


performed. Median and mean operating time was 2.5 and 2.3 hours respectively (Range: 1 - 5 hours). Sixteen (24\%) patients were classified as normal BMI and $50(76 \%)$ as overweight and obese (25 overweight and 25 obese). Median and mean BMI were $28 \mathrm{~kg} / \mathrm{m}^{2}$ and $30 \mathrm{~kg} / \mathrm{m}^{2}$ respectively (Range: 18 - 47).

Forty two patients (64\%) had a " 0 " Performance Status (PS), 20 (30\%) had PS 1 and 4 (6\%) had a PS of 2. In total, 24 (36\%) had "non-zero" performance status.

Median preoperative $\mathrm{Hb}$ was 129, dropping to 119 postoperatively.

Mean intraoperative EBL was $227 \mathrm{ml}$ (95\% CI: 189 266) with a median EBL of $188 \mathrm{ml}$ (Range: $10 \mathrm{ml}$ - 900 $\mathrm{ml}$ ). There were no intra or postoperative blood transfusions.

Median and mean LOS was 3.0 and 3.7 days respectively (Range: 2 - 16 days) with 10 (15\%) patients discharged on or before post operative day 2 and an additional 7 (2\%) patients were deemed suitable for discharge on day 2 but for social reasons were unable to be discharged. Thirty eight (58\%) patients were discharged on day 3. Three patients (5\%) had LOS greater than 7 days.

COX 2 inhibitors were prescribed to 58 (88\%) and 62 (94\%) were able to successfully complete EOF and FTS protocol.

There were 3 (5\%) intraoperative complications/adverse events. Two were episodes of bradycardia related to parietal peritoneum stimulation both settling and allowing surgery to proceed. There was 1 intraoperative bladder injury in a patient who underwent an exenterative procedure, being a Jehovah's Witness, having previously undergone an abdomino-perineal resection and pelvic irradiation for colon cancer, presenting with serous corpus cancer and her uterus fixed to the sacrum. The bladder was morbidly fixed to the uterus as a consequence of her previous irradiation and the bladder inadvertently entered during dissection and repaired in 2 layers without sequelae. There was no intraoperative ureteric, bowel or vascular injuries.

Postoperatively, 13 patents (20\%) experienced a total of 24 complications/adverse events based upon our KPI's. There were 6 (9\%) hospital readmissions, 5 (8\%) wound infections, 3 patients (5\%) whose LOS was greater than 7 days, 2 patients (3\%) had an unplanned ICU admission, 2 developed an ileus (3\%), 2 patients (3\%) unplanned return to theatres, 2 patients (3\%) with electrolyte disturbance and 1 each of the following were reported: haemorrhage from ureteric stents and femoral neuropraxia as outlined in Table 2.

One patient (Patient 3) accounted for 5 of 23 (22\%) complications. Only 2 patients (patient 3 and patient 10) experienced complications greater than grade 2. Patient 3 was a 61 year old, obese Jehovah's Witness described above with a past history of abdomino-perineal resection and pelvic irradiation for colon cancer. She was diagnosed with a serous corpus cancer and her uterus was fixed onto the sacrum as a consequence of previous treatments. Intraoperatively ureteric stents were inserted. Post operative bleeding from ureteric stents required her return to the operating room by the Urology team for removal of ureteric stents, and monitoring in ICU and subsequent readmission to hospital for management of an electrolyte disturbance. Patient 10 was a 60 year old morbidly obese woman who underwent repair of an incisional hernia by general surgical colleagues at the same time as her uterine cancer surgery. She underwent extensive soft tissue mobilisation and was readmitted 3 weeks after surgery with a wound infection that required debridement in the operating room and VAC dressing placement.

\section{DISCUSSION}

Patients commonly ask their surgeon "have you done this before?" and "am I going to be OK?" The answer to these questions are not derived from published RCTs, rather they are derived from clinical audit of personal experience.

Clinical audit is one of the fundamental principles of clinical governance, the process by which clinicians improve the quality of the care they provide. The process involves regularly collecting and measuring activity and outcomes, and analysing and comparing these outcomes with current or "recognised standards", together with a rigorous peer review process. It makes clinicians accountable to the public, by constantly monitoring and maintaining high standards, being transparent and accountable for those standards, identifying problems and addressing them and to constantly improve on those standards to improve overall quality of care. It is what the public expect [7]. The key feature of audit is that it involves reviewing actual and all surgical performance outcomes. In lay terms, the purpose of audit is to confirm that your outcomes are, what you say or think they are [8]. It has been shown quite clearly from cardiac surgery that structured data collection, analysis, and feedback to clinicians improves the quality of outcomes [9].

Our study provides the first real base-line or "recognised standard" on laparotomy patients managed by FTS for the surgical management of uterine cancer.

In this audit, all patients with a diagnosis of uterine corpus malignancy and managed by a FTS program were included. During the study period there were no patients who underwent laparoscopy and as such this audit represents extensive experience of fast track surgical care in patients with uterine malignancy managed by laparotomy and thus serves as a "recognised standard". 
Table 2. Intraoperative and postoperative quality indicators.

\begin{tabular}{|c|c|c|c|c|c|c|c|}
\hline Pt & Age & LOS & PS & BMI & Grade & $\begin{array}{l}\text { Complication/Adverse } \\
\text { Event }\end{array}$ & Comment \\
\hline \multicolumn{8}{|c|}{ Intraoperative Complications } \\
\hline 1 & 80 & 13 & 1 & 40 & 2 & Bradycardia & $\begin{array}{l}\text { Elderly obese woman, developed bradycardia during packing. } \\
\text { Surgery continued. ICU monitoring. Developed post opera- } \\
\text { tive ileus, UTI, wound infection, resulting in increased LOS }\end{array}$ \\
\hline 2 & 66 & 6 & 0 & 26 & 2 & Bradycardia & Bradycardia settled spontaneously. Surgery continued. \\
\hline 3 & 61 & 16 & 0 & 30 & 1 & Bladder injury & $\begin{array}{l}\text { Jehovah's Witness with past history of abdomino-perineal } \\
\text { resection and pelvic irradiation for colon cancer. Uterus fixed } \\
\text { on sacrum. Intraoperative bladder injury. Repaired in } 2 \text { layers, } \\
\text { no sequelae }\end{array}$ \\
\hline \multicolumn{8}{|c|}{ Postoperative Complications } \\
\hline 1 & 80 & 13 & 1 & 40 & 2 & $\begin{array}{l}\text { ICU Admission } \\
\quad \text { Ileus } \\
\text { Wound infection } \\
\text { LOS }>7 \text { days }\end{array}$ & $\begin{array}{l}\text { Elderly obese woman, developed bradycardia during packing. } \\
\text { Surgery continued. ICU monitoring. Developed post opera- } \\
\text { tive ileus, wound infection, resulting in increased LOS }\end{array}$ \\
\hline 3 & 61 & 16 & 0 & 30 & 3 & $\begin{array}{l}\text { Haematuria/haemorrhage } \\
\text { Return to theatre } \\
\text { ICU Admission } \\
\text { LOS }>\text { 7days } \\
\text { Hospital readmission }\end{array}$ & $\begin{array}{l}\text { Jehovah's Witness with past history of abdomino-perineal } \\
\text { resection and pelvic irradiation for colon cancer. Uterus fixed } \\
\text { on sacrum. Ureteric stents inserted. Post operative bleeding } \\
\text { from ureteric stents requiring return to OR by Urology team } \\
\text { for removal of stents. Monitoring in ICU. Subsequent read- } \\
\text { mission to hospital for management of electrolyte disturbance }\end{array}$ \\
\hline 4 & 58 & 3 & 0 & 38 & 2 & Wound infection & $\begin{array}{l}\text { Diagnosed } 4 \text { weeks post op. Treated with oral antibiotics by } \\
\text { GP }\end{array}$ \\
\hline 5 & 57 & 3 & 0 & 29 & 2 & Wound infection & $\begin{array}{l}\text { Wound haematoma/infection treated with oral antibiotics by } \\
\text { GP. No sequelae }\end{array}$ \\
\hline 6 & 43 & 4 & 0 & 23 & 1 & Hospital readmission & Constipation. Readmitted but no specific management \\
\hline 7 & 61 & 3 & 0 & 25 & 1 & Hospital readmission & $\begin{array}{l}\text { Unable to void after catheter removal. Readmitted } 1 \text { week } \\
\text { post op for successful trial of void }\end{array}$ \\
\hline 8 & 61 & 3 & 0 & 40 & 1 & Hospital readmission & Resuture vaginal vault \\
\hline 9 & 46 & 2 & 0 & 29 & 2 & $\begin{array}{l}\text { Hospital readmission } \\
\text { Wound infection }\end{array}$ & $\begin{array}{l}\text { Readmitted with wound infection, conservatively managed } \\
\text { with IV antibiotics and VAC dressing }\end{array}$ \\
\hline 10 & 60 & 6 & 1 & 43 & 3 & $\begin{array}{l}\text { Hospital readmission } \\
\text { Wound Infection } \\
\text { Return to theatre }\end{array}$ & $\begin{array}{l}\text { Readmission with wound infection } 3 \text { weeks after extensive } \\
\text { wound mobilization for repair of incisional hernia in obese } \\
\text { patient. Return to theatre for wound debridement and VAC } \\
\text { dressing }\end{array}$ \\
\hline 11 & 59 & 2 & 1 & 17 & 1 & Other & Femoral neuropraxia, settled prior to discharge \\
\hline 12 & 61 & 3 & 1 & 28 & 1 & Electrolyte & Raised creatinine. Settled prior to discharge \\
\hline 13 & 68 & 10 & 2 & 34 & 2 & $\begin{array}{l}\text { Electrolyte } \\
\quad \text { Ileus } \\
\text { LOS }>7 \text { days }\end{array}$ & $\begin{array}{l}\text { Preexisting CRF, post operative electrolyte disturbance, and } \\
\text { ileus settling with conservative management. Length of stay } \\
10 \text { days }\end{array}$ \\
\hline
\end{tabular}

CRF: Chronic renal failure; VAC: Vacuum assisted closure; ICU: Intensive care unit; LOS: Length of stay; UTI: Urinary tract infection; GP: General practitioner.

The extended experience confirms our earlier work that the majority of patients can complete a FTS program, with minimal morbidity and a low incidence of readmission and as a consequence, a shorter hospital stays [5].

In a health care and financial environment where monetary constraints are ever increasing and medical technology is becoming more complex and expensive, clinicians and hospital administrators need to have access to audit data to confirm whether investment in expensive technology provides an enhanced outcome. It is noteworthy that the LOS and outcomes in the audit patients reported in this article were not too dissimilar to those reported in recent RCTs comparing laparotomy and laparoscopy [10-13].

This audit provides a baseline data set for a large group of patients with uterine corpus cancer operated upon with laparotomy and managed by FTS. It allows for subsequent data to be compared against and as such is a 
powerful tool for the gynaecological oncologist embarking upon surgery for cancer of the uterine corpus.

\section{ACKNOWLEDGEMENTS}

The authors acknowledge financial support from The Chris O’Brien Lifehouse at RPA.

\section{REFERENCES}

[1] AIHW (Australian Institute of Health and Welfare) \& AACR (Australasian association of cancer registries) (2008) Cancer in Australia: An overview, Cancer series, 46.

[2] Kitchener, H., Swart, A.M., Qian, Q., Amos, C. and Parmar, M.K. (2009) Efficacy of systematic pelvic lymphadenectomy in endometrial cancer (MRC ASTEC trial): A randomised study. Lancet, 10, 373, 125-36.

[3] Kehlet, H. (2009) Principles of fast track surgery. Multimodal perioperative therapy programme. Chirurg, 80, 687-689. doi:10.1007/s00104-009-1675-2

[4] Kehlet, H. and Wilmore, D.W. (2002) Multimodal strategies to improve surgical outcome. American Journal of Surgery, 183, 630-641. doi:10.1016/S0002-9610(02)00866-8

[5] Carter, J., Szabo, R., Sim, W., Pather, S., Philp, S., Nattress, K., et al. (2010) Fast track surgery in gynaecological oncology. A clinical audit. The Australian and New Zealand Journal of Obstetrics and Gynaecology, 50, 159-163. doi:10.1111/j.1479-828X.2009.01134.x

[6] McDonnell, J., O’Donnell, B., Curley, G., Heffernan, A., Power, C. and Laffey, J. (2007) The analgesic efficacy of transverse abdominis plane block after abdominal surgery: A prospective randomized controlled trial. Anesthesia and Analgesia, 104, 193-197. doi:10.1213/01.ane.0000250223.49963.0f
[7] Scally, G. and Donaldson, L. (1998) Clinical governance and the drive for quality improvement in the new NHS in England. British Medicine Journal, 4, 61-65.

[8] RACS. (2008) A Guide by the Royal Australian College of Surgeons. Royal Australian College of Surgeons Statement, Surgical Audit and Peer Review.

[9] Grover, F.L., Shroyer, A.L, Hammermeister, K., Edwards, F.H., Ferguson, T.B., Dziuban, S.W., et al. (2001) A decade's experience with quality improvement in cardiac surgery using the veterans affairs and society of thoracic surgeons national databases. Annual Surgery, 234, 464472. doi:10.1097/00000658-200110000-00006

[10] Janda, M., Gebski, V., Brand, A., Hogg, R., Jobling, T., Land, R., et al. (2010) Quality of life after total laparoscopic hysterectomy versus total abdominal hysterectomy for stage I endometrial cancer (LACE): A randomised trial. The Lancet Oncology, 16, 1-9.

[11] Kornblith, A.B., Huang, H.Q., Walker, J.L., Spirtos, N.M., Rotmensch, J. and Cella, D. (2009) Quality of life of patients with endometrial cancer undergoing laparoscopic international federation of gynecology and obstetrics staging compared with laparotomy: A Gynecologic Oncology Group Study. Journal of Clinical Oncology, 27, 5337-5542. doi:10.1200/JCO.2009.22.3529

[12] Mourits, M., Bijen, C., Art, H., Brugge H.T., Sijde, R.V.D., Paulsen, et al. (2010) Safety of laparoscopy versus laparotomy in early-stage endometrial cancer: A randomised trial. Lancet Oncology, 16, 1-9.

[13] Walker, J.L., Piedmonte, M.R., Spirtos, N.M., Eisenkop, S.M., Schlaerth, J.B., Mannel, R.S., et al. (2009) Laparoscopy compared with laparotomy for comprehensive surgical staging of uterine cancer: Gynecologic oncology group study LAP2. Journal Clinical Oncology, 27, 5331. doi:10.1200/JCO.2009.22.3248 